\title{
The efficacy and safety of bevacizumab beyond first progression in patients treated with first-line mFOLFOX6 followed by second-line FOLFIRI in advanced colorectal cancer: a multicenter, single-arm, phase II trial (CCOG-0801)
}

\author{
Goro Nakayama $\cdot$ Keisuke Uehara $\cdot$ Kiyoshi Ishigure $\cdot$ Hiroyuki Yokoyama $\cdot$ Akiharu Ishiyama \\ Takehiko Eguchi $\cdot$ Kenji Tsuboi $\cdot$ Norifumi Ohashi · Tsutomu Fujii $\cdot$ Hiroyuki Sugimoto • \\ Masahiko Koike • Michitaka Fujiwara $\cdot$ Yuich Ando · Yasuhiro Kodera
}

Received: 24 May 2012/ Accepted: 29 July 2012/Published online: 12 August 2012

(C) The Author(s) 2012. This article is published with open access at Springerlink.com

\begin{abstract}
Purpose The aim of this study was to evaluate the efficacy and safety of the planned continuation of bevacizumab beyond first progression (BBP) in Japanese patients with metastatic colorectal cancer (mCRC).

Methods Previously untreated patients with assessable disease were treated with mFOLFOX6 plus bevacizumab
\end{abstract}

Trial registration This trial was registered in University Hospital Medical Information Network (UMIN), UMIN000006818.

G. Nakayama $(\bowtie) \cdot$ N. Ohashi · T. Fujii · H. Sugimoto ·

M. Koike · M. Fujiwara · Y. Kodera

Department of Gastroenterological Surgery (Surgery II),

Nagoya University Graduate School of Medicine,

65 Tsurumai-cho, Showa-ku, Nagoya, Japan

e-mail: goro@med.nagoya-u.ac.jp

K. Uehara

Department of Surgical Oncology (Surgery I), Nagoya

University Graduate School of Medicine, Nagoya, Japan

K. Ishigure

Department of Surgery, Konan Kosei Hospital, Konan, Japan

H. Yokoyama

Department of Surgery, Komaki City Hospital, Komaki, Japan

A. Ishiyama

Department of Surgery, Okazaki City Hospital, Okazaki, Japan

\section{T. Eguchi}

Department of Surgery, Nakatsugawa City Hospital,

Nakatsugawa, Japan

K. Tsuboi

Department of Surgery, Tosei Hospital, Seto, Japan

Y. Ando

Department of Clinical Oncology and Chemotherapy,

Nagoya University Hospital, Nagoya, Japan until tumor progression, followed by FOLFIRI plus bevacizumab. The primary endpoint of the study was the second progression-free survival (2nd PFS), defined as duration from enrollment until progression after the second-line therapy. Secondary endpoints of the study were overall survival (OS), survival beyond first progression (SBP), progression-free survival (PFS), response rate (RR), disease control rate (DCR), and safety.

Results In the first-line setting, 47 patients treated with mFOLFOX6 plus bevacizumab achieved RR of $61.7 \%$, DCR of $89.4 \%$, and median PFS of 13.1 months $(95 \%$ CI, $8.7-17.5$ months). Thirty-one patients went on to receive a second-line therapy with FOLFIRI plus bevacizumab and achieved RR of $27.6 \%$, DCR of $62.1 \%$, and median PFS of 7.3 months (95\% CI, 5.0-9.6 months). Median 2nd PFS was 18.0 months (95\% CI, 13.7-22.3 months). The median OS and SBP were 30.8 months (95 \% CI, 27.6-34.0 months) and 19.6 months (95\% CI, 13.5-25.7 months), respectively. No critical events associated with bevacizumab were observed during the second-line therapy.

Conclusion The planned continuation of bevacizumab during a second-line treatment, BBP strategy, is feasible for the Japanese mCRC patients.

Keywords Colorectal cancer - Chemotherapy · Bevacizumab beyond progression (BBP)

\section{Introduction}

Colorectal cancer is one of the most common cancers worldwide and remains the third leading cause of cancerrelated mortality in Japan [1,2]. For several years, firstand second-line chemotherapy with 5-fluorouracil (5-FU) and folinic acid (FA) in combination with either irinotecan 
(FOLFIRI) or oxaliplatin (FOLFOX) had been the standard therapy for metastatic colorectal cancer (mCRC) [3, 4]. More recently, these combinations are used together with bevacizumab, a humanized monoclonal antibody that binds to and neutralizes vascular endothelial growth factor (VEGF). Benefits of adding bevacizumab to either the established first-line or second-line chemotherapeutic regimens have been robustly documented in previous clinical trials. Regarding the first-line treatment, Hurwitz et al. reported that addition of bevacizumab to fluorouracil-based combination chemotherapy showed significantly better clinical outcomes as compared with chemotherapy alone (overall survival [OS]: 20.3 vs. 15.6 months [hazard ratio [HR]: $0.66 ; P<0.001]$, progression-free survival [PFS]: 10.6 vs. 6.2 months [HR: $0.54 ; P<0.001$ ], and response rate [RR]: 44.8 vs. $34.8 \%[P=0.004])$ [5]. Kabbinavar et al. reported that addition of bevacizumab to fluorouracil/ leucovorin (FU/LV) improved survival as compared with FU/LV alone (OS: 17.9 vs. 14.6 months [HR: 0.74; $P=0.008$ ], PFS: 8.8 vs. 5.6 months [HR: 0.63 ; $P<$ or $=0.0001]$, RR: 34.1 vs. $24.5 \%$ [P=0.019]) [6]. Furthermore, Saltz et al. reported that addition of bevacizumab to oxaliplatin-based chemotherapy significantly improved PFS, although OS did not reach statistical significance, and the RR was not improved (PFS: 9.4 vs. 8.0 months [HR: $0.83 ; \quad P=0.0023$ ], OS: 21.3 vs. 19.9 months [HR: $0.89 ; P=0.077]$ ] [7]. In the second-line setting, the RR rate of various chemotherapeutic regimens has not been satisfactory, ranging from $4 \%$ for FOLFIRI after the first-line FOLFOX6 to $15 \%$ for FOLFOX6 after the first-line FOLFIRI and $20 \%$ for XELOX after irinotecan-based therapies [8, 9]. Again, benefit of adding bevacizumab was demonstrated in several clinical trials in this setting. Giantonio et al. reported that bevacizumab plus FOLFOX4 showed significantly better survival data compared with FOLFOX4 alone after the first-line irinotecanbased treatment (OS 12.9 vs. 10.8 months [HR: 0.75; $P=0.011$ ], PFS 7.3 vs. 4.7 months [HR: $0.61 ; P<0.001$ ], RR: 22.7 vs. $8.6 \%[P<0.001])$ [10]. Bennouna et al. showed that bevacizumab plus irinotecan-based regimens showed efficacy with acceptable safety profile after the firstline oxaliplatin-based treatments (PFS: 7.8, OS: 22.4, and RR: $33 \%$ ) [11].

More recently, a survival benefit associated with the continuous use of bevacizumab beyond progression (BBP) was generated by two large studies. A large observational cohort study that evaluated the efficacy and safety of bevacizumab in combination with chemotherapy (BRiTE study) indicated that the BBP could contribute to prolong the OS [12]. The Avastin registry: investigation of effectiveness and safety (ARIES) also looked at the role of BBP and indicated trend toward longer OS among patients who received bevacizumab beyond first progression compared with patients who received bevacizumab only after progression (27.5 vs. 18.7 months) [13]. However, these are observational studies, and true benefits and risks of $\mathrm{BBP}$ are yet to be shown in a prospective clinical trial, particularly in Japan. This prompted us to conduct a multicenter phase II study of mFOLFOX6 plus bevacizumab followed by FOLFIRI plus bevacizumab in mCRC to explore the BBP strategy for the first time in the Japanese population.

\section{Patients and methods}

\section{Patients}

The study inclusion criteria were histologically confirmed colorectal adenocarcinoma; unrespectable metastatic disease; age 20 years or older; Eastern Cooperative Oncology Group (ECOG) performance status of 0 or 1 ; no previous chemotherapy for $\mathrm{mCRC}$; bidimensionally measurable disease; a life expectancy of at least 3 months; adequate organ function (white blood cell count 3,000-12,000 cells per $\mu \mathrm{L}$, neutrophilic cell count $\geq 1,500$ cells per $\mu \mathrm{L}$, platelet count $\geq 100,000$ per $\mu \mathrm{L}$, aspartate aminotransferase [AST] $\leq 100 \mathrm{IU} / \mathrm{L}$, alanine aminotransferase $[\mathrm{ALT}] \leq 100 \mathrm{IU} / \mathrm{L}$, total bilirubin $\leq 25.7 \mu \mathrm{mol} / \mathrm{L} \quad[\leq 15 \mathrm{mg} / \mathrm{L}]$, and creatinine $\leq 106.1 \mu \mathrm{mol} / \mathrm{L}[\leq 12 \mathrm{mg} / \mathrm{L}])$. Exclusion criteria were pregnancy or lactation; second non-colorectal cancer; complications such as ileus, uncontrolled diabetes mellitus, or hypertension; severe diarrhea; clinically evident gastrointestinal hemorrhage; and ascites or pleural effusion needing treatment. The protocol of this study was approved by the institutional review board or ethics committee of each institution. The study was conducted in compliance with the Declaration of Helsinki. Written informed consent was obtained from all patients participating in the study.

\section{Treatment plan}

As the first-line setting for $\mathrm{mCRC}$, the patients received bevacizumab plus mFOLFOX6 therapy (consisting of bevacizumab $\left[5 \mathrm{mg} / \mathrm{kg}\right.$ ], oxaliplatin $\left[85 \mathrm{mg} / \mathrm{m}^{2}\right]$, and folinic acid $\left[200 \mathrm{mg} / \mathrm{m}^{2}\right]$ followed by bolus infusion of fluorouracil $\left[400 \mathrm{mg} / \mathrm{m}^{2}\right.$ ] and subsequent continuous infusion of fluorouracil $\left[2,400 \mathrm{mg} / \mathrm{m}^{2}\right]$, repeated every 2 weeks) until disease progression, unacceptable toxicity, or patient's wish to terminate the treatment. In the subsequent secondline setting, the patients received bevacizumab plus FOLFIRI therapy (consisting of bevacizumab [5 mg/ $/ \mathrm{kg}$, irinotecan $\left[150 \mathrm{mg} / \mathrm{m}^{2}\right]$, and folinic acid $\left[200 \mathrm{mg} / \mathrm{m}^{2}\right]$ followed by bolus infusion of fluorouracil $\left[400 \mathrm{mg} / \mathrm{m}^{2}\right.$ ] and subsequent continuous infusion of fluorouracil $\left[2,400 \mathrm{mg} / \mathrm{m}^{2}\right]$, 
repeated every 2 weeks) until disease progression, unacceptable toxicity, or patient's wish to terminate the treatment.

Surgical treatment of the metastatic lesions was allowed in patients with sufficient objective response that rendered the lesions resectable.

\section{Assessments}

The primary objective of this study was the second progression-free survival (2nd PFS), defined as the time duration from the date of initiation of the first-line therapy until investigator-assessed disease progression or patient death due to any cause after starting the second-line treatment. If the patient could not receive second-line treatment for medical reasons or refusal, progression-free survival (PFS) on first-line therapy was used. Secondary objectives were OS (the time duration from the date of initiation of each therapy to death due to any cause), survival beyond first progression (SBP) (the time duration from the date of first disease progression to death due to any cause), PFS (the time duration from the date of initiation of each therapy to disease progression or death due to any cause), RR (the proportion of patients who achieved a best response of either a complete response [CR] or partial response $[\mathrm{PR}]$ during each therapy), disease control rate (DCR) (the proportion of patients with CR, PR, or stable disease [SD] during each therapy), and safety. Schematic of patients observation periods is presented in Fig. $1 \mathrm{~b}$. Adverse events were assessed using National Cancer Institute Common Toxicity Criteria (NCI-CTC), version 3.0. In addition, the frequency of bevacizumab-related adverse events (gastrointestinal perforation, wound healing complications, bleeding, hypertension, proteinuria, and thromboembolic events) was assessed.

\section{Statistical analysis}

Assuming a threshold for 2nd PFS of 10.5 months and an expected 2nd PFS of 15.8 months, referring to data from the previous clinical trials, and a 2-year enrollment period and a 2-year follow-up period, 44 patients in total were required to ensure an alpha error of 0.05 (one-sided) and detection power $(1-\beta)$ of $80 \%$. Taking possible dropouts into consideration, the sample size of this study was determined as 50 . The 2 nd PFS, the primary objective of this study, was estimated using the Kaplan-Meier method, and the median 2nd PFS and its $95 \%$ confidence interval were estimated. Other time-to-endpoint data, PFS and OS, were also estimated in the same manner. RR, DCR, and the toxicities were calculated as proportions with exact confidence intervals.

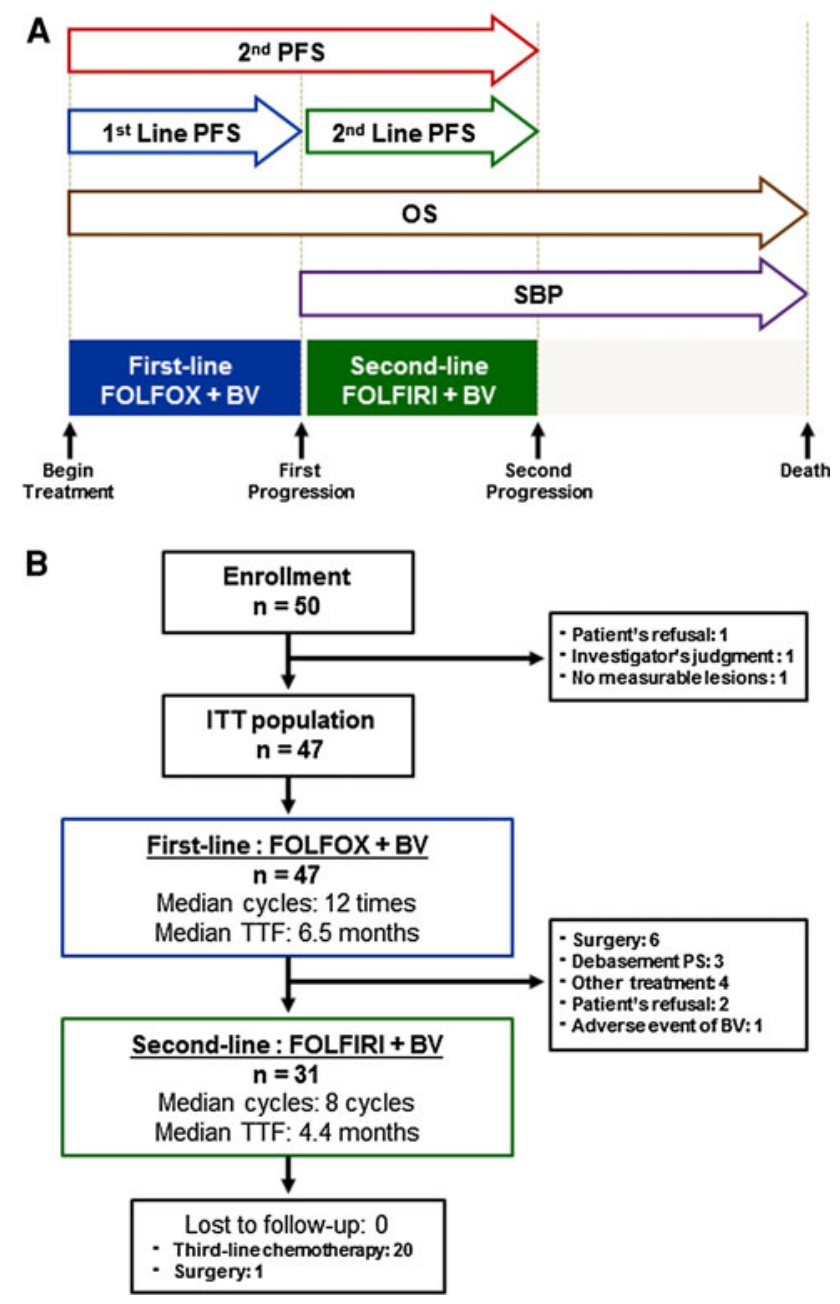

Fig. 1 Schematic of patient observation periods (a) and consort chart of the patients (b). a The second progression-free survival (2nd PFS) is measured from the start of first-line treatment to disease progression after second-line treatment. Progression-free survival (PFS) of each therapy is measured from the start of each therapy to disease progression. Survival beyond first progression (SBP) is measured from the first progression to death. Overall survival (OS) is measured from the start of first-line treatment to death. b Fifty patients were enrolled in this study. Three patients were excluded from the study. Forty-seven patients who received the protocol treatment were included in the safety evaluation

\section{Results}

\section{Patient characteristics}

Fifty patients from 12 institutions in Japan were enrolled in this study from August 2008 to May 2010. Three patients were excluded from the study: one due to the patient's refusal, one due to the investigator's decision, and one due to no measurable lesions as per the inclusion criteria. Forty-seven patients who received the protocol treatment were included in the evaluation of efficacy and safety. Baseline characteristics and consort chart of the patients are presented in Table 1 and Fig. $1 b$. 
Table 1 Patient characteristics

\begin{tabular}{|c|c|c|}
\hline Parameter & $\begin{array}{l}\text { No. of patients } \\
(N=47)\end{array}$ & $\%$ \\
\hline \multicolumn{3}{|l|}{ Age, years } \\
\hline Median & 63 & \\
\hline Range & $40-74$ & \\
\hline \multicolumn{3}{|l|}{ Sex } \\
\hline Male & 31 & 66.0 \\
\hline Female & 16 & 34.0 \\
\hline \multicolumn{3}{|c|}{ Performance status WHO } \\
\hline 0 & 29 & 61.7 \\
\hline 1 & 18 & 38.3 \\
\hline \multicolumn{3}{|l|}{ Primary site } \\
\hline Colon & 31 & 66.0 \\
\hline Rectum & 16 & 34.0 \\
\hline \multicolumn{3}{|l|}{ Metastases } \\
\hline Synchronous & 7 & 14.9 \\
\hline Metachronous & 40 & 85.1 \\
\hline \multicolumn{3}{|l|}{ Metastatic sites } \\
\hline Liver & 21 & 44.6 \\
\hline Lung & 21 & 44.6 \\
\hline Peritoneum & 1 & 2.1 \\
\hline Lymph nodes & 10 & 21.3 \\
\hline \multicolumn{3}{|c|}{ Adjuvant chemotherapy } \\
\hline No & 27 & 57.4 \\
\hline Yes & 20 & 42.6 \\
\hline 5FU-based & 20 & 42.6 \\
\hline Oxaliplatin-based & 0 & 0 \\
\hline
\end{tabular}

No/N number, WHO World Health Organization, 5FU 5-fluorouracil

\section{Treatment status}

As the first-line treatment, 47 patients received a median of 12 cycles (range 2-39) of bevacizumab plus mFOLFOX6 therapy. Median time-to-treatment failure (TTF) was 6.5 months (95\% CI, 4.0-9.0 months). The median relative dose intensity (RDI) for bevacizumab and oxaliplatin was 88 and $76 \%$. Treatment was discontinued because of disease progression in 21 patients $(44.7 \%$ ), adverse events in 14 patients $(29.8 \%)$, and patient's refusal in two patients $(4.3 \%)$. Secondary surgery to remove metastases was performed in six patients $(12.8 \%)$.

As for the second-line treatment, 31 patients received a median of eight cycles (range, 2-28) of bevacizumab plus FOLFIRI therapy. Median TTF was 4.4 months (95\% CI, 2.4-6.4 months). The median RDI for bevacizumab and irinotecan was 80 and $76 \%$. Treatment was discontinued because of disease progression in 20 patients $(64.5 \%)$ and adverse events in two patients $(6.5 \%)$. Secondary surgery to remove metastases was performed in one patient $(3.2 \%)$. After undergoing the second-line protocol treatment, 20
Table 2 Treatment status

\begin{tabular}{|c|c|c|}
\hline & $\begin{array}{l}\text { First-line therapy } \\
(\mathrm{mFOLFOX6}+\mathrm{BV}) \\
(N=47)\end{array}$ & $\begin{array}{l}\text { Second-line therapy } \\
(\text { FOLFIRI }+\mathrm{BV}) \\
(N=31)\end{array}$ \\
\hline \multicolumn{3}{|l|}{ Treatment cycle (times) } \\
\hline Median & 12 & 7 \\
\hline Range & $2-39$ & $2-26$ \\
\hline \multicolumn{3}{|c|}{ Time-to-treatment failure (month) } \\
\hline Median & 6.5 & 3.8 \\
\hline $95 \% \mathrm{CI}$ & $4.0-9.0$ & $2.7-4.5$ \\
\hline \multicolumn{3}{|c|}{ Median relative dose intensity $(\%)$} \\
\hline Bevacizumab & 88 & 80 \\
\hline Oxaliplatin & 76 & - \\
\hline Irinotecan & - & 76 \\
\hline \multicolumn{3}{|c|}{ Reasons for discontinuation (\%) } \\
\hline $\begin{array}{l}\text { Progression of } \\
\text { disease }\end{array}$ & 44.7 & 64.5 \\
\hline Toxicity & 29.8 & 6.5 \\
\hline $\begin{array}{l}\text { Secondary surgery for } \\
\text { metastasis }(\%)\end{array}$ & 12.8 & 3.2 \\
\hline
\end{tabular}

$B V$ bevacizumab, $N$ number, $C I$ confidence interval

patients $(64.5 \%)$ received a third-line chemotherapy, of which the regimen delivered to six patients $(19.4 \%)$ was cetuximab.

There was no therapy-related death in this study. Treatment status is summarized in Table 2.

\section{Clinical outcomes}

After a median follow-up period of 35.9 months (range, 24.2-44.8 months), 39 disease progressions (83.0\%) and 26 deaths $(55.3 \%)$ occurred in the 47 patients enrolled.

Median 2nd PFS, the primary endpoint, was 18.0 months (95\% CI, 13.7-22.3 months) (Fig. 2a).

Median OS was 30.8 months (95\% CI, 27.7-34.0 months) (Fig. 2c), and median SBP was 19.6 months (95\% CI, 13.5-25.7 months) (Fig. 2d).

In the first-line bevacizumab plus mFOLFOX6 therapy, RR and DCR of the 47 patients were 61.7 and $89.4 \%$, respectively (five patients had CR, 24 patients had PR and 13 patients had SD) (Table 3). The median PFS from the initiation of the first-line therapy was 13.1 months (95\% CI, 8.7-17.5 months) (Fig. 2b).

In the second-line bevacizumab plus FOLFIRI therapy, RR and DCR of the 31 patients who went on to the second-line therapy were 29.0 and $64.5 \%$, respectively (two patients had $\mathrm{CR}$, seven patients had PR, and 11 patients had SD) (Table 3). The median PFS from the initiation of the second-line therapy was 7.3 months (95\% CI, 5.0-9.6 months) (Fig. 2b). 

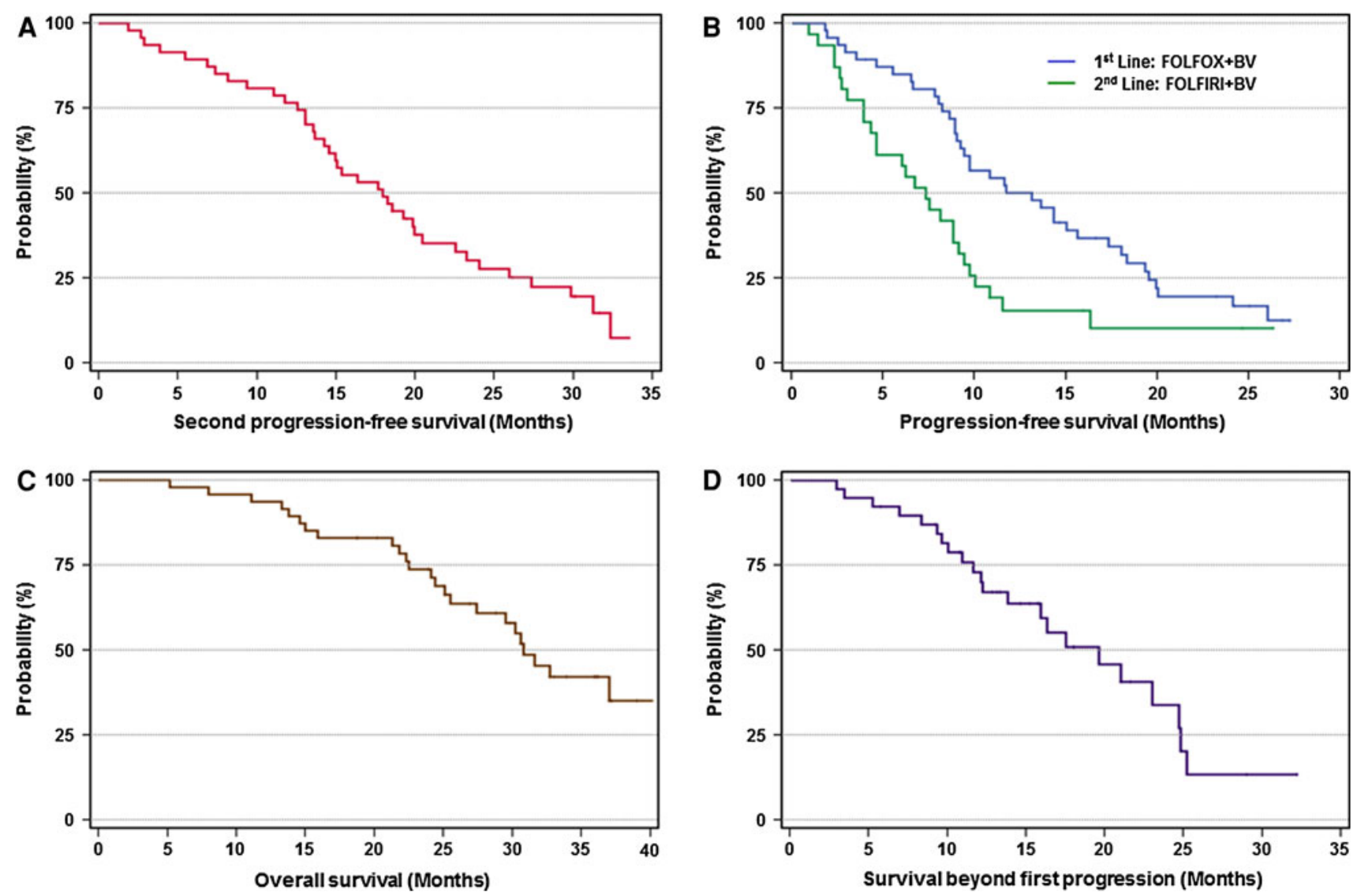

Fig. 2 Survival outcomes. a Median second progression-free survival, the primary endpoint, was 17.7 months (95\% CI, 13.4-22.0 months). b Median progression-free survivals were 13.1 months $(95 \% \mathrm{CI}$, 8.7-17.5 months) in the first-line setting and 7.5 months $(95 \% \mathrm{CI}$, 4.9-10.2 months) in the second-line setting. $\mathbf{c}$ Median overall survival

was 30.6 months (95\% CI, 13.4-22.0 months). d Median survival beyond the first progression was 17.7 months (95\% CI, 13.422.0 months). Survival curves were estimated using Kaplan-Meier methods

\section{Adverse events}

Frequency of common toxicities is presented in Table 4. The incidences of hematologic and non-hematologic $>$ grade 3 toxic events were 44.4 and $16.7 \%$. The hematologic toxic events (>grade 3 ) occurred in 10 patients $(50 \%$ ) in the firstline therapy and six patients $(37.5 \%)$ in the second-line therapy. The non-hematologic toxic events (>grade 3) occurred in five patients $(25 \%)$ in the first-line therapy and no patient $(0 \%)$ in the second-line therapy.

Severe adverse events associated with bevacizumab during the first-line therapy were grade 3 GI perforation in one case $(2 \%)$, grade 2 venous thromboembolic event in one case $(2 \%)$, and grade 2 bleeding event in one case $(2 \%)$. However, no critical events associated with bevacizumab were observed during the second-line therapy. There was a higher incidence of new or worsening hypertension in the second-line therapy as compared with the first-line therapy ( 26 vs. $45 \%$ ).

\section{Discussion}

This is the first prospective study to examine the continuous use of bevacizumab in combination with FOLFIRI after failing the first-line treatment with mFOLFOX/ bevacizumab combination in the Japanese patients with $\mathrm{mCRC}$. There are several issues regarding the use of $\mathrm{BBP}$ that needs to be clarified; the response and survival benefit obtained through adding bevacizumab to each line of chemotherapy, the survival benefit of the BBP strategy per $s e$, and the adverse effect of long-term exposure to bevacizumab among patients who received BBP. Of these, benefits in terms of response rate and survival by adding bevacizumab to either the first-line oxaliplatin-based chemotherapy or second-line irinotecan-based chemotherapy have been well documented in previous clinical trials [7, 11]. In the current study, the response and survival data observed both in the first-line and second-line settings seem to compare favorably with these studies, with a RR of 
Table 3 Objective tumor response

\begin{tabular}{lccllr}
\hline Response & \multicolumn{2}{l}{$\begin{array}{l}\text { First-line therapy } \\
(N=47)\end{array}$} & & \multicolumn{2}{l}{$\begin{array}{l}\text { Second-line therapy } \\
(N=31)\end{array}$} \\
\cline { 2 - 3 } & No. of patients & $\%$ & & No. of patients & $\%$ \\
\hline CR & 5 & 10.6 & 2 & 6.5 \\
PR & 24 & 51.1 & 7 & 22.6 \\
SD & 13 & 27.7 & 11 & 35.5 \\
PD & 5 & 10.6 & 11 & 35.5 \\
RR $(\%)$ & 61.7 & & 29.0 & \\
DCR $(\%)$ & 89.4 & & 64.5 & \\
\hline
\end{tabular}

No/N number, $C R$ complete response, $P R$ partial response, $S D$ stable disease, $P D$ progressive disease, $R R$ response rate $(\mathrm{CR}+\mathrm{PR}), D C R$ disease control rate $(\mathrm{CR}+\mathrm{PR}+\mathrm{SD})$

$61.7 \%$ and a PFS of 13.1 months in the first-line setting, and a RR of $29.0 \%$ and a PFS of 7.5 months in the secondline setting.

In general, failure to respond to chemotherapy with cytotoxic agents implies inherent or acquired resistance to the therapy and leads to a change in the therapeutic regimen. The mechanisms of the resistance to cytotoxic agents are typically consequences of genetic instability inherent in cancer that renders mutant cells insensitive to chemotherapeutic agents. In contrast, the mechanisms of resistance to biologic targeted agents, including bevacizumab, are not well understood. One hypothesis that forms the basis of BBP is that persistent VEGF suppression continues to have clinical benefit when given in combination with the secondary and tertiary cytotoxic regimens. This hypothesis was supported by the results of several clinical trials exploring benefit of BBP. The first evidence of a survival benefit associated with BBP was generated by a large, observational study, BRiTE study. In this study, the patients who had been treated with BBP had a superior median SBP and OS (19.2 and 31.8 months, respectively) as compared with those who were treated without BBP $(9.5$ and 19.9 months, respectively) [12]. The ARIES study examined the role of bevacizumab after disease progression in patients who had received first-line bevacizumab and in those who were bevacizumab-naive at the time of second-line treatment. The authors observed a trend toward longer SBP and OS in patients who had received first-line and second-line bevacizumab (median SBP: 14.1 and OS: 27.5 months) when compared with patients who received bevacizumab only after the disease progression (median SBP: 7.5 and OS: 18.7 months), while PFS of the secondline treatment was similar in both groups [13].

The primary objective of the current study was to assess the efficacy of BBP determined in terms of the 2nd PFS, defined as the time duration from the initiation of the firstline therapy until disease progression during the second-
Table 4 Frequency of common toxicities

\begin{tabular}{|c|c|c|c|c|}
\hline \multirow[t]{2}{*}{ Toxicity } & \multicolumn{2}{|c|}{$\begin{array}{l}\text { First-line therapy } \\
(N=47)\end{array}$} & \multicolumn{2}{|c|}{$\begin{array}{l}\text { Second-line therapy } \\
(N=31)\end{array}$} \\
\hline & $\begin{array}{l}\text { All grades } \\
(\%)\end{array}$ & $\begin{array}{l}>\text { Grade } \\
3(\%)\end{array}$ & $\begin{array}{l}\text { All grades } \\
(\%)\end{array}$ & $\begin{array}{l}>\text { Grade } \\
3(\%)\end{array}$ \\
\hline Hematologic toxicity & 72.3 & 27.7 & 51.6 & 32.3 \\
\hline Neutropenia & 57.4 & 23.4 & 41.9 & 22.6 \\
\hline Thrombocytopenia & 12.8 & 0 & 9.7 & 0 \\
\hline Anemia & 23.4 & 0 & 9.7 & 0 \\
\hline Febrile neutropenia & - & 4.3 & - & 3.2 \\
\hline $\begin{array}{l}\text { Non-hematologic } \\
\text { toxicity }\end{array}$ & 85.1 & 25.5 & 51.6 & 12.9 \\
\hline Diarrhea & 0 & 0 & 12.9 & 3.2 \\
\hline Nausea/vomiting & 27.7 & 4.3 & 19.4 & 0 \\
\hline Mucositis & 10.6 & 2.1 & 12.9 & 3.2 \\
\hline Hand-foot syndrome & 2.1 & 0 & 0 & 0 \\
\hline Alopecia & 2.1 & 0 & 3.2 & 0 \\
\hline Fatigue & 6.4 & 0 & 3.2 & 3.2 \\
\hline Neuropathy & 72.3 & 17.0 & 19.4 & 3.2 \\
\hline Allergy & 12.8 & 2.1 & 3.2 & 0 \\
\hline $\begin{array}{l}\text { Bevacizumab- } \\
\text { associated } \\
\text { toxicity }\end{array}$ & 51.1 & 2.1 & 45.2 & 3.2 \\
\hline Hypertension & 25.5 & 0 & 45.2 & 3.2 \\
\hline Proteinuria & 21.3 & 0 & 16.1 & 0 \\
\hline Bleeding & 2.1 & 0 & 3.2 & 0 \\
\hline Infection & 2.1 & 0 & 0 & 0 \\
\hline Thrombosis & 2.1 & 0 & 0 & 0 \\
\hline GI perforation & 2.1 & 2.1 & 0 & 0 \\
\hline
\end{tabular}

$N$ number, GI gastrointestinal

line of chemotherapy. Tournigand et al. reported that the median 2nd PFS was 10.9 months when the first-line FOLFOX and second-line FOLFIRI were administered, both without bevacizumab, and this was a historical benchmark to design our study. The median 2nd PFS of 17.7 months as shown in this study met our expectations and clearly pointed to an improvement in the outcome compared with the historical precedent setting without bevacizumab. There could be an argument that the endpoint of a chemotherapeutic strategy such as BBP that constitutes from several lines of treatment should be OS. In this aspect, the median OS and SBP in this study were 30.8 and 19.6 months, respectively. These survival data are potentially comparable with the results observed in the BBP population from the previous studies.

Safety of a long-term exposure to bevacizumab among patients who received BBP is another issue explored in this study. The safety outcomes in the BRiTE study showed no apparent increase in serious adverse events reported in the BBP group compared with the no-BBP group [12, 14], with the exception of thromboembolic event in the elderly 
population [15]. Such thromboembolic event was rare at $2 \%$ in the current Japanese population. Other severe adverse events associated with bevacizumab were grade 2 bleeding event ( $2 \%$ ) and grade 3 GI perforation $(2 \%)$, all of which occurred during the first-line chemotherapy. Thus, no critical events associated with bevacizumab were observed during the second-line therapy. It is of note that a higher incidence of new or worsening hypertension was observed during the second-line therapy compared with the first-line therapy. The higher cumulative incidence of hypertension in the BBP group was not unexpected, given that the risk of developing bevacizumab-associated hypertension appears to accumulate over time and that the BBP results in substantially longer bevacizumab exposure. The type and frequency of other grade 3/4 events (including neutropenia, diarrhea, vomiting, and asthenia) were consistent with the known safety profile of the chemotherapy regimens.

Our study is merely hypothesis-generating regarding the efficacy of BBP because of the one-arm design and relatively small sample size. However, it does imply that the BBP strategy is beneficial to the Japanese population with the 2nd PFS nearly 10 months longer than that observed in the Tournigand study and SBP and OS that is similar to the survival data observed in the BRiTE study and the ARIES study. Data regarding safety of the BBP strategy was more robust, in which only hypertension was to be carefully taken care of. From these encouraging data, it can now be recommended that a randomized study involving a larger numbers of patients be performed in Japan to obtain hard evidence regarding the efficacy of BBP.

In summary, the planned continuation of bevacizumab during the second-line treatment is feasible for the Japanese mCRC patients. A prospective randomized control study to confirm the efficacy is warranted.

Conflict of interest The authors have declared no conflicts of interest.

Open Access This article is distributed under the terms of the Creative Commons Attribution License which permits any use, distribution, and reproduction in any medium, provided the original author(s) and the source are credited.

\section{References}

1. Boyle P, Levin B (2008) World cancer report. IARC, Lyon

2. Kayama T, Sobue T (2010) Cancer statistics in japan. Foundation for Promotion of Cancer Research, Tokyo

3. Saltz LB, Cox JV, Blanke C, Rosen LS, Fehrenbacher L, Moore MJ, Maroun JA, Ackland SP, Locker PK, Pirotta N, Elfring GL, Miller LL (2000) Irinotecan plus fluorouracil and leucovorin for metastatic colorectal cancer. N Engl J Med 343:905-914

4. Giacchetti S, Perpoint B, Zidani R, Le Bail N, Faggiuolo R, Focan C, Chollet P, Llory JF, Letourneau Y, Coudert B, Bertheaut-
Cvitkovic F, Larregain-Fournier D, Le Rol A, Walter S, Adam R, Misset JL, Lévi F (2000) Phase III multicenter randomized trial of oxaliplatin added to chronomodulated fluorouracil-leucovorin as first-line treatment of metastatic colorectal cancer. J Clin Oncol 18:136-147

5. Hurwitz H, Fehrenbacher L, Novotny W, Cartwright T, Hainsworth J, Heim W, Berlin J, Baron A, Griffing S, Holmgren E, Ferrara N, Fyfe G, Rogers B, Ross R, Kabbinavar F (2004) Bevacizumab plus irinotecan, fluorouracil, and leucovorin for metastatic colorectal cancer. N Engl J Med 350:2335-2342

6. Kabbinavar FF, Hambleton J, Mass RD, Hurwitz HI, Bergsland E, Sarkar S (2005) Combined analysis of efficacy: the addition of bevacizumab to fluorouracil/leucovorin improves survival for patients with metastatic colorectal cancer. J Clin Oncol 23:3706-3712

7. Saltz LB, Clarke S, Díaz-Rubio E, Scheithauer W, Figer A, Wong R, Koski S, Lichinitser M, Yang TS, Rivera F, Couture F, Sirzén F, Cassidy J (2008) Bevacizumab in combination with oxaliplatin-based chemotherapy as first-line therapy in metastatic colorectal cancer: a randomized phase III study. J Clin Oncol 26:2013-2019

8. Tournigand C, André T, Achille E, Lledo G, Flesh M, MeryMignard D, Quinaux E, Couteau C, Buyse M, Ganem G, Landi B, Colin P, Louvet C, de Gramont A (2004) FOLFIRI followed by FOLFOX6 or the reverse sequence in advanced colorectal cancer: a randomized GERCOR study. J Clin Oncol 22:229-237

9. Rothenberg ML, Cox JV, Butts C, Navarro M, Bang YJ, Goel R, Gollins S, Siu LL, Laguerre S, Cunningham D (2008) Capecitabine plus oxaliplatin (XELOX) versus 5-fluorouracil/folinic acid plus oxaliplatin (FOLFOX-4) as second-line therapy in metastatic colorectal cancer: a randomized phase III non inferiority study. Ann Oncol 19:1720-1726

10. Giantonio BJ, Catalano PJ, Meropol NJ, O'Dwyer PJ, Mitchell EP, Alberts SR, Schwartz MA, Benson AB 3rd, Eastern Cooperative Oncology Group Study E3200 (2007) Bevacizumab in combination with oxaliplatin, fluorouracil, and leucovorin (FOLFOX4) for previously treated metastatic colorectal cancer: results from the Eastern cooperative oncology group study E3200. J Clin Oncol 25:1539-1544

11. Bennouna J, Borg C, Delord JP, Husseini F, Trillet-Lenoir V, Faroux R, François E, Ychou M, Goldwasser F, Bouché O, Senellart H, Kraemer S, Douillard JY (2012) Bevacizumab combined with chemotherapy in the second-line treatment of metastatic colorectal cancer: results from the phase II BEVACOLOR study. Clin Colorectal Cancer 11:38-44

12. Grothey A, Sugrue MM, Purdie DM, Dong W, Sargent D, Hedrick E, Kozloff M (2008) Bevacizumab beyond first progression is associated with prolonged overall survival in metastatic colorectal cancer: results from a large observational cohort study (BRiTE). J Clin Oncol 26:5326-5334

13. Bekaii-Saab TS, Bendell JC, Cohn AL et al. (2010) Bevacizumab (BV) plus chemotherapy (CT) in second-line metastatic colorectal cancer (mCRC): initial results from ARIES, a second BV observational cohort study (OCS). J Clin Oncol 28(15s): abstract 3595

14. Kozloff M, Yood MU, Berlin J, Flynn PJ, Purdie DM, Ashby MA, Dong W, Sugrue MM, Grothey A, Investigators of the BRiTE study (2009) Clinical outcomes associated with bevacizumab-containing treatment of metastatic colorectal cancer: the BRiTE observational cohort study. Oncologist 14: 862-870

15. Kozloff MF, Berlin J, Flynn PJ, Kabbinavar F, Ashby M, Dong W, Sing AP, Grothey A (2010) Clinical outcomes in elderly patients with metastatic colorectal cancer receiving bevacizumab and chemotherapy: results from the BRiTE observational cohort study. Oncology 78:329-339 